\title{
A Multi-Agent Framework for Operation of a Smart Grid
}

\author{
Ruchi Gupta ${ }^{1}$, Deependra Kumar Jha ${ }^{1}$, Vinod Kumar Yadav ${ }^{1}$, Sanjeev Kumar ${ }^{2}$ \\ ${ }^{1}$ School of Electrical, Communication and Electronics Engineering, Galgotias University, Uttar Pradesh, India \\ ${ }^{2}$ School of Basic and Applied Sciences, Department of Mathematics, Galgotias University, Uttar Pradesh, India \\ Email: ruchibsr@rediffmail.com
}

Received March, 2013

\begin{abstract}
This paper presents the operation of a Multi-agent system (MAS) for the control of a smart grid. The proposed Multi-agent system consists of seven types of agents: Single Smart Grid Controller (SGC), Load Agents (LAGs), a Wind Turbine Agent (WTAG), Photo-Voltaic Agents (PVAGs), a Micro-Hydro Turbine Agent (MHTAG), Diesel Agents (DGAGs) and a Battery Agent (BAG). In a smart grid LAGs act as consumers or buyers, WTAG, PVAGs, MHTAG \& DGAGs acts as producers or sellers and BAG act as producer/consumer or seller/buyer. The paper demonstrates the use of a Multi-agent system to control the smart grid in a simulated environment. In order to validate the performance of the proposed system, it has been applied to a simple model system with different time zone i.e. day time and night time and when power is available from the grid and when there is power shedding. Simulation results show that the proposed Multi-agent system can perform the operation of the smart grid efficiently.
\end{abstract}

Keywords: Multi-agent System; Smart Grid; Micro-grid; Distributed Generation; Renewable Energy

\section{Introduction}

The security and resiliency of electric power supply to serve critical facilities are of high importance in today's world. In India, with the increasing complexity of power grids, growing demand and growing concerns for environment accentuate the leap towards something 'smarter'. Instead of building large electric power grids and high capacity transmission lines an intelligent approach is essential for transforming the existing power grid to a 'smarter grid' widely referred as 'smart grid'. Smart grid technologies have the potential to transform the existing grids to more efficient, self healing, reliable, safer and less constrained grids [1].

A smart micro-grid can be defined as a low voltage distribution network with distributed energy resource (DER) units, such as the distributed generation (DG) units and distributed storage (DS) units and loads. The DG units utilize Diesel Engines, Micro turbines, Fuel Cells, Photovoltaic (PV) panels, small wind turbines, and combined heat and power (CHP) systems. The capacity of the DG sources varies from few $\mathrm{kW}$ to 1-2 MW. The DS units could be flywheels, energy capacitors and batteries.

The micro-grid can be made smarter by integrating advanced sensing technologies, control methods and communication techniques [1-3]. Smart grids can benefit customers through providing uninterruptible power, enhancing local reliability, reducing transmission loss, and supporting local voltage and frequency.

As the DER units typically operate at a distribution voltage level and geographically close to loads, smart micro-grids are developed to interconnect the energy sources and loads in a relatively small area, such as a suburban community, a university or school, a commercial area, and an industrial site. Besides the environmental benefit of using more renewable energy sources, a smart grid can either be interconnected to the main grid as a single aggregated load (or generator) or in case of external faults or periods of emergency, it has the capability to separate, or island, from the main grid and operate independently, within limits.

Significant research works have been carried out on operation and control of smart grid. Current trends to control and monitor the operation of electrical power systems are however moving towards the use of an automated agent technology, known as multi-agent system. In recent years, multi-agent based approach is proposed/adopted to provide intelligent energy control and management systems in smart grids. Multi-agent systems have become the focus of intense research in European countries $[4,5]$.

In India, a lot is yet to be done towards making power grids smarter and reliable, capable of taking self correcting decisions for optimal scheduling of generation resources. In this paper the operation of a multi-agent system for the control of a smart grid is described in an Indian scenario.

Present power scenario of India is described in Section II. The rest of the paper is organized as follows: Section 
III gives the Multi-agent approach to smart grid operation. Multi-agent technology is shortly introduced. An overview of the related work, general management and control concept based on the related work is presented with the help of a process flow-chart. In Section IV Simulation results are presented based on the proposed approach. Section V concludes the paper.

\section{Present Power Scenario of India}

The relationship between power consumption and national economic development has a great significance. Indian power sector is facing challenges and despite significant growth in generation over the years, it has been suffering from shortages and supply constraints. All India region-wise generating installed capacity (MW) of power utilities is given in Table 1 [6] and the corresponding pie chart is shown in Figure 1.

India's electricity sector is amongst the world's most active players in renewable energy utilization, especially wind energy. As of December 2011, India had an installed capacity of about $22.4 \mathrm{GW}$ of renewal technologies-based electricity. In1990, the capacity of renewable energy sources (RES) was $18 \mathrm{MW}$ whereas the genera- tion during the year 1989-1990 was 6 MU in India. Initially, the annual capacity addition was very slow, but from 2008 onwards the contribution from RES is considerable. In 2012, the RES capacity was 24503. $45 \mathrm{MW}$ and the percentage share of RES in total generation capacity was $12.26 \%$ which is expected to increase to $17.12 \%$ by 2017 . The percentage share of RES in total generation in India during 2011-12 was around 5.5\%.

The category-wise details of electricity generation in the country during August 2012 and during April 2012 to August 2012 are given below in Table 2 [7].

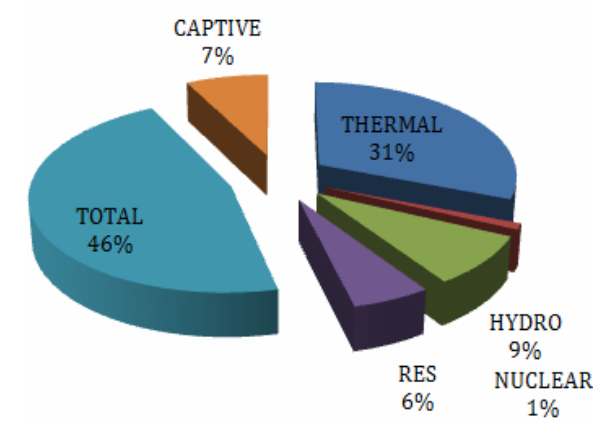

Figure 1. All India Generating Installed Capacity (MW).

Table 1. Region -wise Electricity Generating Capacity of India.

\begin{tabular}{|c|c|c|c|c|c|c|c|c|c|}
\hline \multirow{2}{*}{ S.N. } & \multirow{2}{*}{ Region } & \multicolumn{4}{|c|}{ Thermal } & \multirow{2}{*}{ Nuclear } & \multirow{2}{*}{ Hydro } & \multirow{2}{*}{ RES } & \multirow{2}{*}{ Total } \\
\hline & & Coal & Gas & Diesel & Total & & & & \\
\hline 1 & Northern & 31623.50 & 4671.26 & 12.99 & 36307.75 & 1620.00 & 15467.75 & 4623.24 & 58018.74 \\
\hline 2 & Western & 43537.00 & 8254.81 & 17.48 & 51809.29 & 1840.00 & 7447.50 & 8450.04 & 69546.83 \\
\hline 3 & Southern & 23782.50 & 4962.78 & 939.32 & 29684.60 & 1320.00 & 11353.03 & 12096.78 & 54454.41 \\
\hline 4 & Eastern & 22607.88 & 190.00 & 17.20 & 22815.08 & 0.00 & 3948.12 & 436.71 & 27199.91 \\
\hline 5 & North Eastern & 60.00 & 824.20 & 142.74 & 1026.94 & 0.00 & 1200.00 & 243.28 & 2470.22 \\
\hline 6 & Islands & 0.00 & 0.00 & 70.02 & 70.02 & 0.00 & 0.00 & 6.10 & 76.12 \\
\hline 7 & Total & 121610.88 & 18903.00 & 1199.75 & 141713.68 & 4780.00 & 39416.40 & 25856.14 & 211766.22 \\
\hline
\end{tabular}

Capacitive Generation Capacity in Industries having demand of $1 \mathrm{MW}$ and above, Grid interactive (as on 31-03-2011) = 34444.12 MW

Table 2. Electricity generation in India (category-wise).

\begin{tabular}{|c|c|c|c|}
\hline Category & $\begin{array}{l}\text { Monitored capacity } \\
\text { (MW) }\end{array}$ & $\begin{array}{c}\text { Actual Generation (MU) during } \\
\text { August2012 }\end{array}$ & $\begin{array}{l}\text { Actual Gen (MU) during } \\
\text { April2012 to August2012 }\end{array}$ \\
\hline \multicolumn{4}{|l|}{ RES } \\
\hline Wind & 14870.955 & 4508.687 & 18909.007 \\
\hline Solar & 976.904 & 83.483 & 539.205 \\
\hline Biomass & 707.250 & 105.995 & 781.449 \\
\hline Small Hydro & 1290.293 & 330.083 & 1059.842 \\
\hline Others & 131.760 & 7.900 & 83.246 \\
\hline Total RES & 20858.372 & 5279.702 & 23557.744 \\
\hline Total (conventional) & 181710.520 & 74498.360 & 382466.050 \\
\hline Total & 202568.892 & 79778.062 & 406023.794 \\
\hline
\end{tabular}




\section{Multi-Agent Based Operation of Smart Grid}

\subsection{Multi-Agent System}

A multi-agent system is a combination of several agents working in collaboration pursuing assigned tasks to achieve the overall goal of the system. The multi-agent system has become an increasingly powerful tool in developing complex systems that take advantages of agent properties: autonomy, sociality, reactivity and pro-activity. The multi-agent system is social-able in that they interact with other agents via some kind of agent communication language. The agents also perceive and react to their environment. Lastly, the multi-agent system is proactive in that they are able to exhibit goal-oriented behavior by taking initiatives [1-4, 8-12].

In the context of power systems, multi-agent technologies can be applied in a variety of applications, such as to perform power system disturbance diagnosis, power system restoration, power system secondary voltage control and power system visualization. Some of the recent researchers have implemented multi-agent system to control the operation of a smart grid.

\subsection{Agent Model of the Proposed Smart Grid}

The proposed model of the smart grid consists of several agents that communicate and coordinate with each other. The smart grid model that is used in the proposed application is simple, since we focus mainly on the cooperation of agents. Figure 2 shows the architecture of the smart grid. Smart grid is connected to the main grid. The Smart Grid Controller announces the time zone (day/ night) and availability of grid. The production units that belong to the smart grid adjust their set points based on their availability, the time zone, availability of the grid, grid price, their operational cost and the load demand [1].

a) Load Agent (LAG)

LAG is installed at each load centre. Main functions of LAG are:

i. Load Forecasting: LAG makes a prediction about the demand of next day. The forecast demand for electricity is determined from the historical data and the weather forecast for tomorrow.

ii. Sending Message: LAG sends a request message to SGC for the power purchase. The message includes the amount of power and its price.

iii. Receiving Message: LAG receives from SGC a message that tells from where to purchase the electric power.

b) Battery Agent (BAG)

BAG, installed at each battery centre, has attributes such as the amount of charge, the capacity and the status (charge/discharge). The following describes the main functions of BAG. i. Measurement of the state of charge: BAG conducts to measure the amount of battery charge. Battery is charged when Grid is available and discharged when Grid is not available.

ii. Sending Message: BAG sends a request message to SGC for the power purchase or sale. The message includes the amount of power and its price.

iii. Receiving Message: BAG receives from SGC a message that tells when to purchase or sale the electric power.

c) Smart-Grid-Controller (SGC)

SGC, a special purpose agent facilitates the negotiation process of the multi-agent system. The following describes the main functions of the SGC.

i. Controlling the timing of the negotiation: SGC suggests the timing of the negotiation by sending a message to open the market to all agents in the smart grid.

ii. Decision making of the operation: SGC makes a decision of the operation of producer or producer/consumer agents.

d) Wind Turbine Agent (WTAG)

WTAG, installed at each wind turbine generator, has attributes such as the generator available power. The following describes the main functions of WTAG.

i. $\quad$ Sending Message: WTAG sends a request message to $\mathrm{SGC}$ for the power sale. The message includes the amount of power and its price.

ii. Receiving Message: WTAG receives from SGC a message that tells where to sale the electric power.

e) Photo-Voltaic Agent (PVAG)

PVAG, installed at each photo-voltaic generator, has attributes such as the generator available power. The following describes the main functions of PVAG.

i. $\quad$ Sending Message: PVAG sends a request message to SGC for the power sale. The message includes availability, the amount of power and its price.

ii. Receiving Message: PVAG receives from SGC a message that tells where to sale the electric power.

f) Micro-Hydro Turbine Agent (MHTAG)

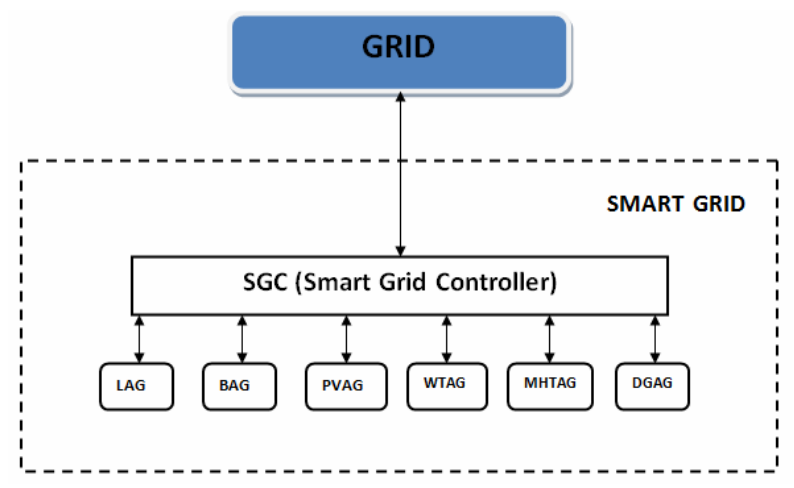

Figure 2. Agent model of the proposed smart grid 
MHTAG, installed at each micro-hydro turbine generator, has attributes such as the generator available power. The following describes the main functions of MHTAG.

i. Sending Message: MHTAG sends to SGC a message to request for the power sale. The message includes the amount of power and its price.

ii. Receiving Message: MHTAG receives from SGC a message that tells where to sale the electric power.

g) Diesel Generator Agent (DGAG)

DGAG, installed at each diesel generator, has attributes such as the generator minimum/maximum output value. The following describes the main functions of DGAG.

i. Sending Message: DGAG sends to SGC a message to request for the power sale. The message includes the amount of power and its price.

ii. Receiving Message: DGAG receives from SGC a message that tells where and when to sale the electric power.

h) Steps for Sorting Process

The sorting algorithm (flow chart as shown in Figure 3) for available generating resources (producers) is explained as below:

Step 1: Collect the following data of the available sources/ producers:

(i) Power cost per unit

(ii) Availability of the producer

(iii) Power availability with the producer

Assign ID in numeric to the producer(s).

Step 2:

(i) Sort the array of producers in the order of price

(ii) The producers which are available and can give power at that time slot are sorted in ascending order of cost/price.

Step3: Read the Demand (Load).

Step 4: Identify the producers which can fulfill the demand using the array sorted in Step 2, individually or in combination.

Step 5: Send the producer ID and capacity to SGC.

i) Negotiation Process

Negotiation is one of the key processes for the multiagent system to successfully attain its goal. Flow-chart in Figure 4 shows the negotiation process.

There are seven types of agents in the proposed system viz. SGC, LAG, BAG, PVAG, WTAG, MHTAG and DGAG.

The main objective is to fulfill the demand (load) at a particular time by minimizing the use of diesel generators as their per unit price outreach other available sources. To accomplish this, the agents are required to cooperate and coordinate so that they make efficient use of the power supplied by other sources at the time of power shedding.

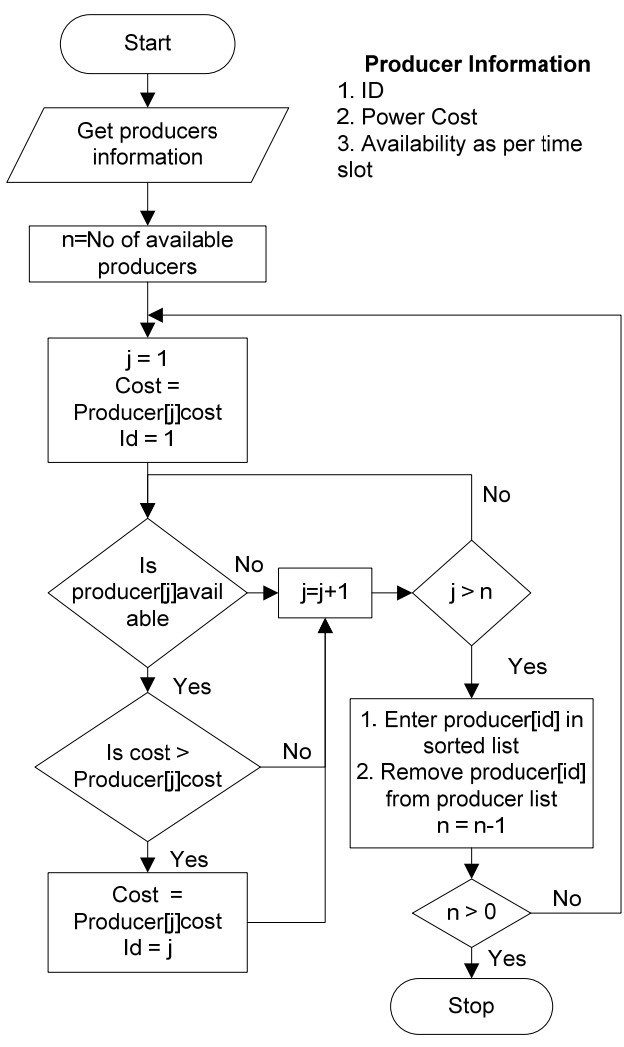

Figure 3. Flow-chart for sorting of producers (Generating units) for SGC

SGC is informed about the demand, producer availability and the operating cost per unit of different producers in one negotiation cycle. At the time of power shedding, if the electrical power in the smart grid is insufficient, demand is fulfilled by the diesel generators. SGC sends a message of announcement of tender to all agents in the smart grid every 10 minutes. SGC is suggested to control the timing of the negotiation process. All buyer agents in the smart grid reply a message of purchase of electrical power. The message includes the amount of electrical power i.e. Demand 'D'. All producer agents in the smart grid reply a message of sale of electrical power. The message includes the generator available power, their availability at a particular time and their operating cost per unit.

In the next step, sorting of producers and the grid is done depending upon their availability and operating costs in ascending order of price per unit. This sorted list is then sent to the SGC that makes a decision on operation of different producers based on this generated list.

The demand is checked with the power available with the producer. If the demand is not fulfilled by first producer, SGC sends operation command to next producer and so on until the demand is fulfilled. Finally, generation load pattern is displayed for a given time period and next negotiation cycle begins. 


\section{Simulation Results}

\subsection{Assumptions}

The case study considers a township located in India. It comprises of 150 houses inhabited with modern amenities, education sector, health centre, super market, elevators, flour mill, laundry, a community hall and water pump. Typical household appliances include lighting, refrigerator, $\mathrm{AC} /$ heater, geyser, $\mathrm{TV}$, washing machine, micro wave, electric cooker i.e. a max load of $5 \mathrm{kVA}$ to $10 \mathrm{kVA}$. Super market facilities include lighting, refrigerator/freezer ( $\max$ consumption $15 \mathrm{~kW}$ ), AC/heater. Medical health centre facilities include lighting, refrigerator, $\mathrm{AC} /$ heater. Education sector facilities include lighting, AC/heater, laboratory equipments.

The Smart Grid consists of a Load Agent (LAG), Wind Turbine Agent (WTAG), two Photo-Voltaic Agents (PVAGs), Micro-Hydro Turbine Agent (MHTAG), two diesel generator agents (DGAGs) and a Battery Agent (BAG). The maximum capacity of each agent is shown in Table 3.

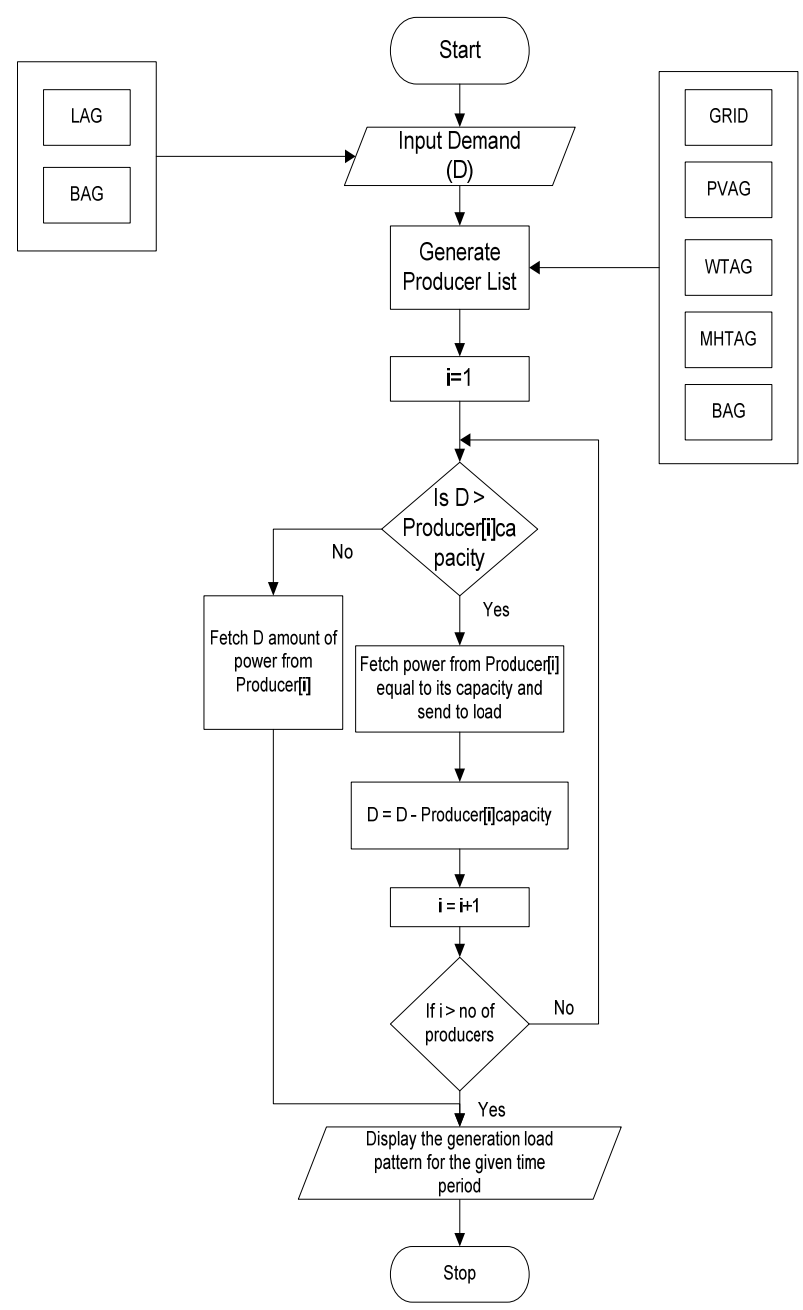

Figure 4. Flow-chart of the negotiation process
Electrical power prices of different producers are given in Table 4 [13]. In India, tariff is same for peak as well as off-peak hours. Due to shortage of electricity, power cuts (power shedding) are common in India. To avoid a total black out of the power system, electricity delivery is stopped for non-overlapping periods of time over different parts of the distribution regions.

Demand power of the LAG, as shown in Figure 5 is the data of township under consideration during day time and night time. Four simulations are carried out on this smart grid model. Table 6 shows the content of the case studies.

Table 3. Parameters.

\begin{tabular}{lll}
\hline Name & Max Capacity & Type \\
\hline LAG & $2 \mathrm{MW}$ (peak),1.5MW (off-peak) & Consumer \\
WTAG & $300 \mathrm{KW}$ & Producer \\
PVAG1 & $150 \mathrm{KW}$ & Producer \\
PVAG2 & $100 \mathrm{KW}$ & Producer \\
MHTAG & $400 \mathrm{KW}$ & Producer \\
DGAG1 & $200 \mathrm{KW}$ & Producer \\
DGAG2 & $200 \mathrm{KW}$ & Producer \\
BAG & $\pm 250 \mathrm{KWh}$ & Producer/consumer \\
GRID & $\infty / 0^{*}$ & Producer \\
\hline
\end{tabular}

" power shedding (no power is available from the grid); ${ }^{* *}$ producer at the time of power shedding \& consumer during charging phase.

Table 4. Power cost per unit

\begin{tabular}{ll}
\hline Producers & Price/unit(kWh) \\
\hline GRID & 4.00 \\
BAG & $4.50^{\#}$ \\
PVAG & $9.18^{*}$ \\
WTAG & $3.84^{* *}$ \\
MHTAG & 5.51 \\
DGAG & 13.00 \\
\hline
\end{tabular}

"Pseudo price (As battery is charged from the grid, the price includes grid price per unit in addition to some maintenance cost; "Solar PV Crystalline; ${ }^{* *}$ wind Zone IV $\left(>400 \mathrm{~W} / \mathrm{m}^{2}\right)$.

Table 5. Availability of the producer(s)

\begin{tabular}{ccccccc}
\hline Time zone & PVAG & GRID & MHTAG & WTAG & BAG & DGAG \\
\hline 06:00-12:00 & Yes & Yes & Yes & Yes & No & Yes \\
12:00-18:00 & Yes & No & Yes & Yes & Yes & Yes \\
18:00-0:00 & No & Yes & Yes & Yes & No & Yes \\
0:00-6:00 & No & No & Yes & Yes & Yes & Yes \\
\hline
\end{tabular}


Table 6. Test Case Scenario

\begin{tabular}{ccc}
\hline Case & Time Zone & $\begin{array}{c}\text { Availability of Power } \\
\text { from Grid }\end{array}$ \\
\hline Case I & Day & Y \\
Case II & Day & N \\
Case III & Night & Y \\
Case IV & Night & N \\
\hline
\end{tabular}

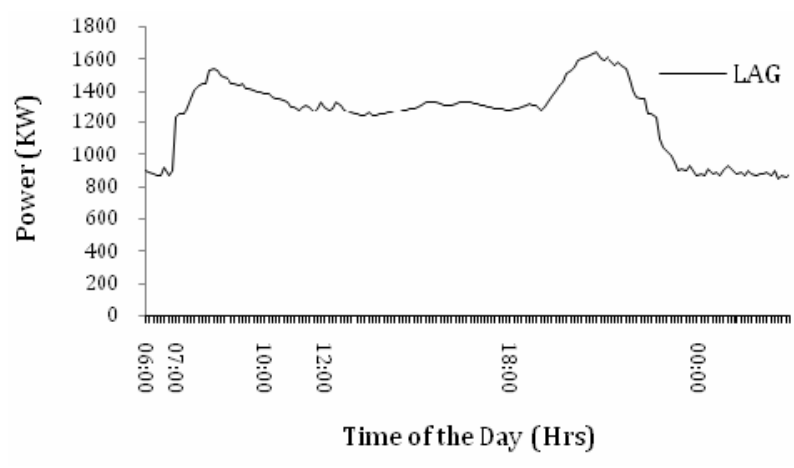

Figure 5. Demand power of LAG (24 hrs)

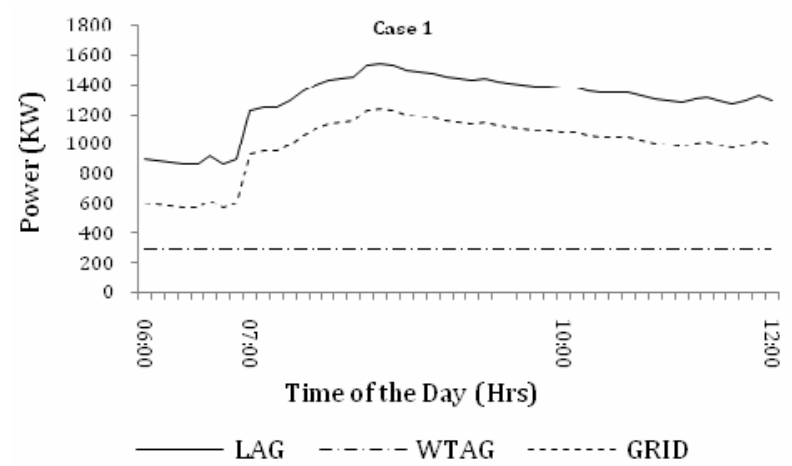

Figure 6. Showing the availability of power from grid during the day time

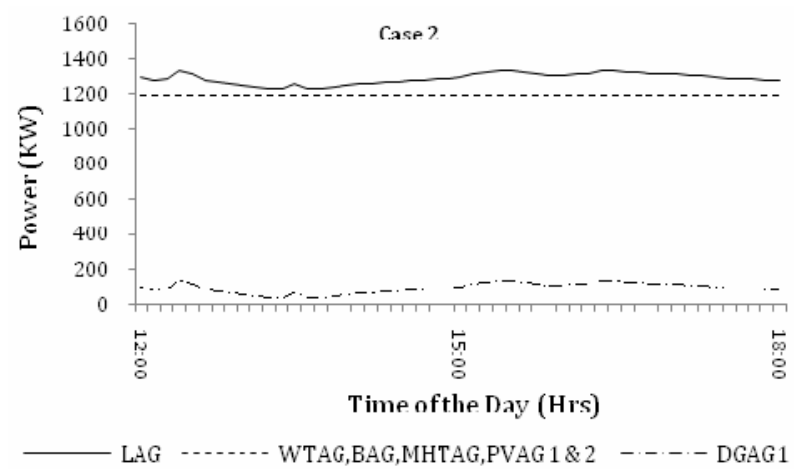

Figure 7. Showing the unavailability of power from grid during the day time

Case1: Day time and power is available from the grid This is the case when grid is available. Any amount of power can be taken from the grid. WTAG price is less compared to grid. SGC takes the decision to fulfill the load demand by WTAG as shown in figure 6 . When the load demand is more compared to the power available by WTAG, power is taken from grid. The demand is fulfilled at a lower price.

Case 2: Day time and power is not available from the grid

This is the case when load demand is more. Due to power shedding power is not available from the grid. Power is taken from WTAG \& BAG and demand is fulfilled as shown in figure 7 . If the demand is not fulfilled by these producers, SGC fetch power from MHTAG, PVAGs \& DGAGs. Load demand is fulfilled at a lower price. Simulation results show that the multi-agent approach is promising in smart grid operations.

Case 3: Night time and power is available from the grid

This is the case when load demand is fluctuating. Any amount of power can be taken from the grid. WTAG price is less compared to grid. SGC takes the decision to fulfill the load demand by WTAG as shown in figure 8 . When the load demand is more compared to the power available by WTAG, power is taken from the grid. Load demand is fulfilled at a lower price.

Case 4: Night time and power is not available from the grid

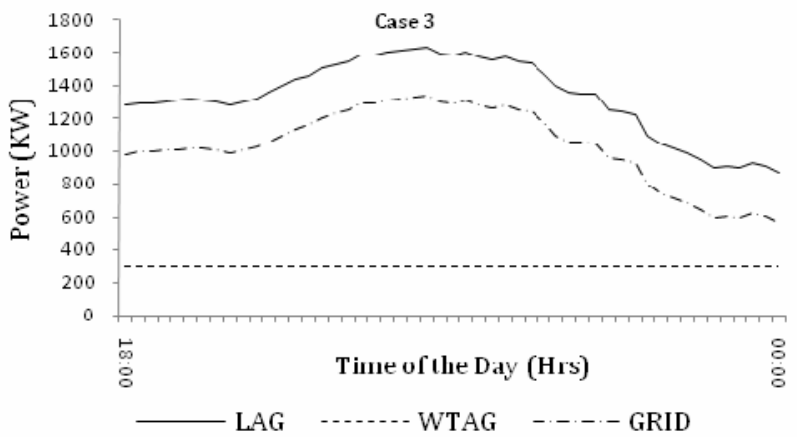

Figure 8. Showing the availability of power from grid during the night time

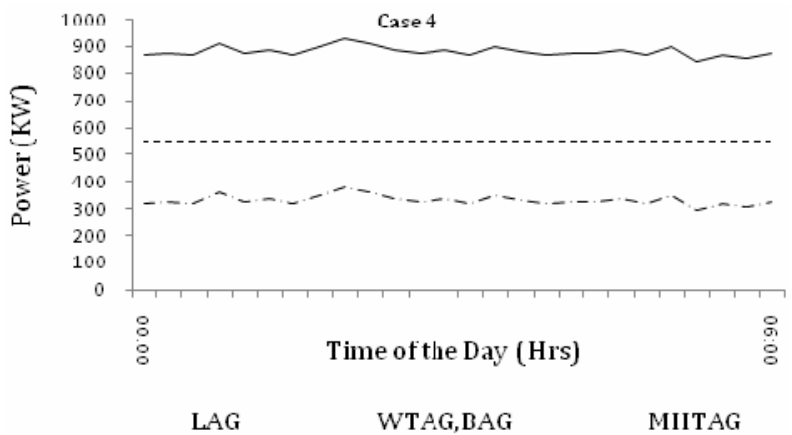

Figure 9. Showing the unavailability of power from grid during night time 
This is the case when load demand is less. Due to power shedding power is not available from the grid. Power is taken from WTAG and BAG and demand is fulfilled as shown in figure 9. If the demand is not fulfilled by these producers SGC fetch power from MHTAG and then from DGAG. Load demand is fulfilled at a lower price. Simulation results show that the multi-agent approach is promising in smart grid operation.

\section{Conclusions}

This paper presents the benefits of multi-agent system for smart grid operation. This is achieved effectively through the negotiation skills and coordination of actions between SGC and various agents. The proposed approach is validated in a simulated environment that considers both the availability and outage conditions of the power grid. Based on the method, the algorithm and various test case scenarios, it is found that the proposed multi-agent approach is viable in smart grid operations.

\section{REFERENCES}

[1] T. Nagata, Y. Ueda and M. Utatani, "A Multi-agent Approach to Smart Grid Operations," The 2012 IEEE Conference on Power System Technology (POWERCON), 2012, pp. 1-5. doi:10.1109/PowerCon.2012.6401303

[2] M. Pipattanasomporn, H. Feroze and S. Rahman, "Multi-Agent Systems in a Distributed Smart Grid: Design and Implementation," Proceedings of IEEE PES 2009 Power Systems Conference and Exposition (PSCE'09), Mar 2009, Seattle, Washington, USA.

[3] J. J. Lu, X. Da and A. Qian, "Research on Smart Grid in China," Proceedings of Transmission \& Distribution Conference \& Exposition: Asia and Pacific, 2009, pp. $1-4$.

[4] A. L. Dimeas and N. D. Hatziargyriou, "Operation of a Multi-agent System for Microgrid Control," IEEE
Transactions on Power systems, Vol. 20, No. 3, 2005, pp. 1447-1455. doi:10.1109/TPWRS.2005.852060

[5] A. L. Dimeas and N. D. Hatziargyriou, "Agent based control of Virtual Power Plants," IEEE The 14th International Conference on Intelligent System Applications to Power Systems, ISAP 2007 November 4 - 8, 2007, Kaohsiung, Taiwan 536.

[6] Available online at: http://www.cea.nic.in/reports/monthly/executive_rep/jan1 3/8.pdf

[7] Available online at: www.cea.nic.in/reports/articles/god/renewable_energy.pd f.

[8] A. Dimeas and N. D. Hatziagyriou, "A Multi-agent System for Micro Grids," In Proc. IEEE PES General Meeting, Denver, CO, Jun. 2004, PESGM2004-001, p. 244.

[9] A. L. Dimeas, S. I. Hatzivasiliadis and N. D. Hatziargyriou, "Control Agents for Enabling Customer-driven Micro Grids," Proceedings of Power \& Energy Society General Meeting, 2009. PES '09. IEEE, 26-30 July 2009, pp. 1-7.

[10] A. L. Dimeas and N. D. Hatziargyriou, "Agent Based Control for Microgrids," Proceedings of IEEE PES General Meeting, Tampa, FL, June 24-28, 2007

[11] S. J. Chatzivasiliadis, N. D. Hatziargyriou and A. L. Dimeas, "Development of an Agent Based Intelligent Control System for Micro Grids," The 2008 IEEE Power and Energy Society General Meeting on Conversion and Delivery of Electrical Energy in the 21st Century, 20-24 July, 2008, pp. 1-6.

[12] A. L. Dimeas and N. D. Hatziargyriou, "A MAS architecture for Micro grids Control," Proceedings of the 13th International Conference on Intelligent Systems Application to Power Systems, 6-10 Nov, 2005. doi:10.1109/ISAP.2005.1599297

[13] Available online at: http://mnre.gov.in/filemanager/UserFiles/september_mon th_2012_rerf.pdf. 